Article

\title{
Drinking Water Consumption Patterns: An Exploration of Risk Perception and Governance in Two First Nations Communities
}

\author{
Neal Spicer *, Brenda Parlee *, Molly Chisaakay and Doug Lamalice \\ Resources Economics and Environmental Sociology, University of Alberta, Edmonton, AB T6G 2R3, Canada; \\ mchisaak@ualberta.ca (M.C.); Cultural.designs@yahoo.ca (D.L.) \\ * Correspondence: NSpicer@ualberta.ca (N.S.); BParlee@ualberta.ca (B.P.)
}

Received: 28 May 2020; Accepted: 21 August 2020; Published: 24 August 2020

check for updates

\begin{abstract}
Many Indigenous communities across Canada suffer from the lack of access to clean drinking water; ensuring individuals and communities have safe water to drink either from their home or from their local environment requires the consideration of multiple factors including individual risk perception. In collaboration with local leaders, semi-structured interviews $(n=99)$ were conducted over a two-year period in the Dene Tha' First Nation and Kát''odeeche First Nation to unpack the issue of risk perception and its meaning to local community members. These local metrics of risk perception including smell, taste, safety, health fears and level of concern were then used to explore patterns in other data on drinking water consumption patterns and bottled water use. The results are consistent with previous research related to water insecurity and indicate that both communities consume more bottled water than the average Canadian. Results also varied by jurisdiction; those in Alberta indicated much higher levels of concern and a greater degree of bottled water consumption.
\end{abstract}

Keywords: indigenous; water security; drinking water; bottled water

\section{Introduction}

Increasing bottled water consumption is a concern in Canada and globally [1,2]. Although some people choose to drink bottled water for convenience or prestige [3], many use bottled water out of necessity due to lack of access to clean drinking water in their homes, communities or local environment [4-8]. In most towns and cities in Canada, potable water is provided as a basic government service; where those services are not provided the cost falls to the individual and household. For First Nations communities, who are already vulnerable to poverty and ill health, such costs seem an unnecessary burden.

Historically, Indigenous communities had access to clean water from lakes, rivers and muskeg; however, the sustainability of these sources is increasingly tenuous due to the impacts of climate change, resource development and other human disturbances as well as the socio-political decisions related to the management of the risks of these environmental problems [9-13]. Access to clean drinking water among Indigenous peoples living on "reserves" in Canada is also a known problem due to lack of adequate drinking water infrastructure and related services $[11,14-16]$. The answers are not simply technical or clinical. Water quality, like other kinds of ecosystem services, can be defined by standardized measures but also has normative dimensions $[17,18]$. In other words, what is important to one community is not necessarily important elsewhere. Indigenous community perceptions of drinking water quality are thus important to understand since they are a major driver of individual decisions to drink local water or buy bottled water. Risk perceptions can vary by numerous factors and norms within communities, the condition of the local environment as well as differences in knowledge systems $[1,19]$. Such perceptions can also vary by jurisdiction depending on government water regulations and related management regimes [20]. 
There are many factors that are known to affect perceptions of drinking water quality including organoleptics (taste, smell), gender, age, education socio-economic status, cultural norms and ecological context (see Literature Review). While there is broad recognition of these factors globally, are these factors able to explain patterns of drinking water consumption in Indigenous communities in the Mackenzie River Basin? Although there are emerging interdisciplinary and solutions-oriented studies that consider cultural perspectives [21-23], the majority of research related to drinking water in Indigenous communities has dealt with technical and regulatory issues of drinking water service and infrastructure. Although there are a growing number of ethnographic and qualitative studies that indicate perception or drinking water quality varies across cultures $[10,22,24]$, few studies have been done at a population scale with the intention of understanding the interconnected factors that affect who and why individuals may be more or less likely to drink bottled water than water from the home or their local environment (i.e., the land). Moreover, consideration of jurisdiction has been a lesser dimension of this body of work. Inspired by surveys used to assess bottled water consumption by First Nations in Ontario and Saskatchewan [4], and in consideration of the value of more qualitative approaches valued in many Indigenous contexts [10], a collaborative project with two First Nations community partners was developed. More specifically, this case study research conducted in 2017-2018 with Kátł'odeeche First Nation in the Northwest Territories and Dene Tha' First Nations in Alberta sought to: (i) determine how risk perception and other social-economic variables influence individual drinking water consumption patterns (including water from the land and water from home); (ii) explore how political jurisdiction and associated infrastructure and regulations influence individual drinking water consumption patterns.

\section{Literature Review}

Lack of clean drinking water for Indigenous communities is symbolic of colonialism; owing to a history of socio-economic marginalization and exclusion from mainstream society, many First Nation communities lack the rights, resources and capacity to address the problem and are trapped in a situation of dependency on the state to provide these services [25].

The state system governing drinking water quality is, however, an imperfect one. The regulation of drinking water on Indian Reserves is particularly complex and multi-layered, involving various government agencies that include Indigenous and Northern Affairs Canada, Health Canada, Environment Canada and local indigenous governments, with each department having their own area of responsibility [6]. The situation is further exacerbated using guidelines and policies versus formal laws and legislation, which results in confusion and lack of overall oversight and established regulatory practices. According to Morales [26], the numerous problems with the current policies for First Nations include regulatory gaps for drinking water on Indigenous reserve lands across Canada, substandard and inadequate water delivery infrastructure, inconsistent water testing, and insufficient community capacity due to improper training for operators, often insufficient funding, and poor monitoring of drinking water facilities to ensure adherence to policies and procedures.

The location of reserves is often problematic, lands designated as Indian Reserves tend to be marginal lands (i.e., not historically valued by settlers) and as a result generally lack good quality natural water sources [27]. Furthermore, the historical treatment and policies of the Federal Government toward First Nations communities, such as residential schools and forced assimilation practices, have reduced the human and social capacities of Indigenous communities, exacerbating the problems associated with drinking water in many communities [28]. Resource extraction in Indigenous traditional territories can also have extensive impacts on water security for the area. Among the issues in the region where the DTFN and KFN are located are contamination from Alberta oil sands activities, logging impacts, as well as the impacts of gold mine including arsenic contamination of surface and ground water near Yellowknife, Northwest Territories [29]. 


\subsection{Drinking Water Patterns: The Trend toward Bottled Water Use}

The consumption of bottled water has been increasing around the world $[1,20,30]$. In Canada, a cross-country survey conducted in 2004 showed that 38 percent of the respondents drink tap water, 40 percent filtered tap water, and 22 percent prefer bottled water as their main source of drinking water [1]. This emerging pattern of increased bottled water usage by individuals has been examined by academics extensively.

However, there has been limited research on the motivations and patterns of the increased bottled water usage within Indigenous communities. The increased levels of bottled water consumption seen within Indigenous communities could perhaps be explained by the fact that the risks are, on average, far greater than non-Indigenous communities $[1,6]$. An example of these increased risks is that, as of 30 November 2017, 95 active long-term (in place for more than 1 year) Drinking Water Advisories (DWAs) and 41 active short-term DWAs (temporary water issue) were in effect in various First Nation communities (not including British Columbia or communities north of the 60th parallel) across Canada [31].

In response to the increased utilization of bottled water there is growing research around the choices and perceptions of their water sources $[1,20,30,32,33]$. The ways in which cultural beliefs, norms and knowledge influences water preferences is also a growing area of research [34-36]. Related areas of work focus on how previous water contamination events (e.g., illness and water advisories) influence perceptions of water safety [37]. However, to date, relatively limited research has focused on the unique socio-economic conditions and risk perceptions of First Nations communities and how these influence drinking water consumption patterns; the majority has been macro in scale with limited attention to the unique socio-economic, ecological and jurisdictional contexts of individual communities [38]. While some research has been done in Alaska, Nunavut and in Labrador, no similar studies have been done with First Nations in Alberta and Northwest Territories [18,39].

\subsection{Drinking Water and Risk Perception}

Risk perception is the subjective judgement that individuals make about the characteristics and severity of a risk. While subjectivity is sometimes dismissed as of limited value in understanding water quality, an emerging number of academics recognize subjective assessment of risks as valuable proxy indicators of environmental quality. Risk perception is also a common framework for understanding drinking water consumption patterns including bottled water use. There are numerous variables that can potentially impact perceived risk including various demographics, level of perceived control, level of trust in institutions, familiarity of the environment, and information that is derived from external sources [20]. Due to reported problems of drinking water in many Indigenous communities, it is hypothesized that risk perception would play a very important part in water consumption patterns. The knowledge and information that Indigenous communities use to evaluate the risks of drinking water from both the land and from the home comes from a variety of sources including water advisories, technical expertise as well as Traditional Knowledge.

It has long been assumed that a lack of information or formal education about the quality of water increased the perception of risk, resulted in an increased consumption of bottled water, and caused a lack of trust in the supplied tap water in some individuals [40]. In research conducted in various First Nation communities, it was shown that an increase in the available information about testing practices and frequency and quality of tap water would make the respondents feel safer about the quality of tap water [15]. This seems to indicate that if people were not aware or had little understanding of this information, there would be a tendency to have a decreased level of trust in the quality of their tap water.

An emerging body of work shows that other kinds of knowledge and expertise also influence the perception of water quality. Unlike other studies who approach communities through a deficit lens, this body of work assumes that local lived experience including experience on the land is a strength that outweighs more technical kinds of assessments. Moreover, such knowledge is more readily considered 
legitimate and meaningful in Indigenous communities. Traditional Knowledge of First Nations and other Indigenous communities has become the basis for the development of indicators for assessment and monitoring of water quality including the risks of drinking water [5].

Previous experiences of poor water quality including advisories on water quality have been shown to have long-term implications on risk perception [37]. Local advisories as well as significant water problems in one's own environment or community can create new or reinforce existing fears about drinking water quality. Water crises and related advisories can also impact many more communities and over a much larger time frame as a result of the amplifying effects of media reporting (e.g., newspapers). The Walkerton water crisis for example, was shown to have impact across Canada [37]. In communities experiencing frequent or chronic water advisories including Indigenous communities and those living in flood zones etc., the situation can be more significant [33]. These heightened perceptions of risks have been tied to increased bottled water consumption [41]. Research in small rural coastal towns that had either experienced boil water advisories and/or water shortages shows that when under the boil water advisories, most of the people used bottled water as their main source of drinking water [23].

\subsection{Risk Perception-Worries about Health and Safety}

While drinking water quality is frequently evaluated according to technical standards in Canada, subjective assessments of water quality including, individual perceptions of whether the water is healthy or safe to drink, are considered equally valuable. This includes subjective evaluation of both source water quality as well as human health implications of drinking poor water. Poor environmental quality has been strongly correlated with individual perceptions that drinking water is also of poor quality [42]. In a survey conducted in the United States and Canada (including First Nations communities from Southern Canada), concerns over the safety of the tap water were also strongly linked to bottled water consumption $[1,4,15,30]$. In some cases, the cause of increased health concern is tied to a particular event or site of perceived or reported water pollution. In research conducted in the Big Sandy Coal Mine region of West Virginia for example, it was shown that health concerns over tap water sources due to pollution from mining was associated with increased bottle water usage [43].

\subsection{The Role of Taste and Smell in Risk Perception}

Prior research and surveys indicate that the taste, color, turbidity and odor of water plays a crucial part in and perceptions drinking water and consequent choices about drinking bottled water; in particular, the taste of water can play a very important role in the decision to drink bottled water [20]. In small rural towns in Saskatchewan, it was found that one or more aesthetic complaint about the tap water significantly correlated to an increased consumption of bottled water [41]. In a cross-Canada survey of various First Nation communities, when examining why individuals thought the tap water was unsafe, various aspects including appearance (14 percent), taste (12 percent) and odor (10 percent) of the water played a major part in perception of risk, including whether the water is healthy or safe to drink [15].

\subsection{Demographics and Socio-Economic Variations in Risk Perception}

Various demographic variables have important relationships to perceived risk. Gender, age, education level, income and others are examined in this paper to see how they relate to people's choices and risk perception regarding drinking water. Studies have shown that women are more likely to drink bottled water. In a survey that was conducted across Canada, it was shown that, despite regional differences, overall 59 percent of women respondents thought that bottled water is safer than tap water [1]. In Spence and Walters's examination of the APS results, it was shown that women were statistically more likely than males to be more concerned about the safety of their tap water [33]. In research conducted in First Nation communities, it was shown that women are more likely to have increased bottled water consumption and higher distrust of water sources in their communities [4]. 
There are conflicting results when it comes to age and its impact on drinking water perceptions. In one study, some areas showed older people drinking more tap water than others, while in other areas, the opposite is true [1]. In the examination of the 2001 APS, it was found that age had no relationship to First Nation participants' response when it came to their perception of the degree of safety of their drinking water [33]. Surveys conducted across Canada indicate that less educated people are more likely to drink filtered water and it was hypothesized that this was because they are less able to assess the health risks of their drinking water; therefore, they were in turn, more likely to believe the claims of safety through home filtration units The same study indicated that individuals with higher education are less likely to drink bottled water as their primary source of water. The researchers felt this may indicate that educated people are more likely to be able to assess the available information and better understanding the viability of the available drinking water sources [1]. The results of a 2001 APS show that higher education is related to greater concerns about the safety of the drinking water [33]. In the case of many First Nation communities, it is hypothesized that individuals with higher levels of education are more likely to drink bottled water due to the high occurrence of problems with drinking water sources in the communities.

There are varying results in previous research on the impacts of income and bottled water consumption. Some research suggests that increased income or availability of money increases the likelihood of drinking bottled water as the primary source [1]. However, in a study of the Appalachian Mountain region—an area with extensive coal mining—showed that where extreme potential health concerns associated with the mines existed, bottle water usage was high regardless of income [43]. In a 2001 APS examination, it was found that income had no effect on the perception of risk for drinking water [33].

\section{Materials and Methods}

\subsection{Setting}

Research was carried out collaboratively with two First Nations communities in the Mackenzie River Basin of Northern Canada (see Figure 1). Dene Tha' First Nation (DTFN) is a community of Cree, Dene and Beaver speaking families. Approximately 1800 people ( 350 households) live in the three communities of Bushe River, Meander River and Chateh; however, there is also a population of Dene Tha' members who live outside of these communities as well. The total region of Dene Tha' territory is currently defined as 74,224 acres; however, their traditional hunting, trapping and fishing territories constitute a much larger area of present-day Alberta, Saskatchewan and the Northwest Territories. A variety of services are provided in these reserve communities, including municipal water services. The Dene Tha' was a signatory group to Treaty 8 in 1900 and received their territorial lands in 1946. The Dene Tha' lived a mainly nomadic lifestyle until a residential school was built in Assumption in the 1950s, and the missionaries encouraged families to settle in permanent settlements [44]. Extensive oil and gas extraction coupled with forestry (pulp and paper production) have created widespread environmental stresses on the DTFN territory [45-47]. The DTFN has water treatment plants in two of its three communities (Meander River and Chateh) and buys water from the city of High Level to provide households in Bushe River. It delivers household water via water truck and water cisterns or pressurized supply lines. There are numerous problems associated with the water delivery process. Along with the lack of regular testing and cleaning of the cisterns, another major problem of contamination stems from flooding. In Chateh, many community households lay within a floodplain, which means that their water cisterns are sometimes polluted by natural water and all the pollutants that may potentially come with it. In fact, at the time of interviewing in the community, homes were having their cisterns cleaned because of flooding that occurred in June 2016. This clearly exacerbates the problems for drinking water. In these three communities, the administration is responsible for testing and cleaning household water supplies. 


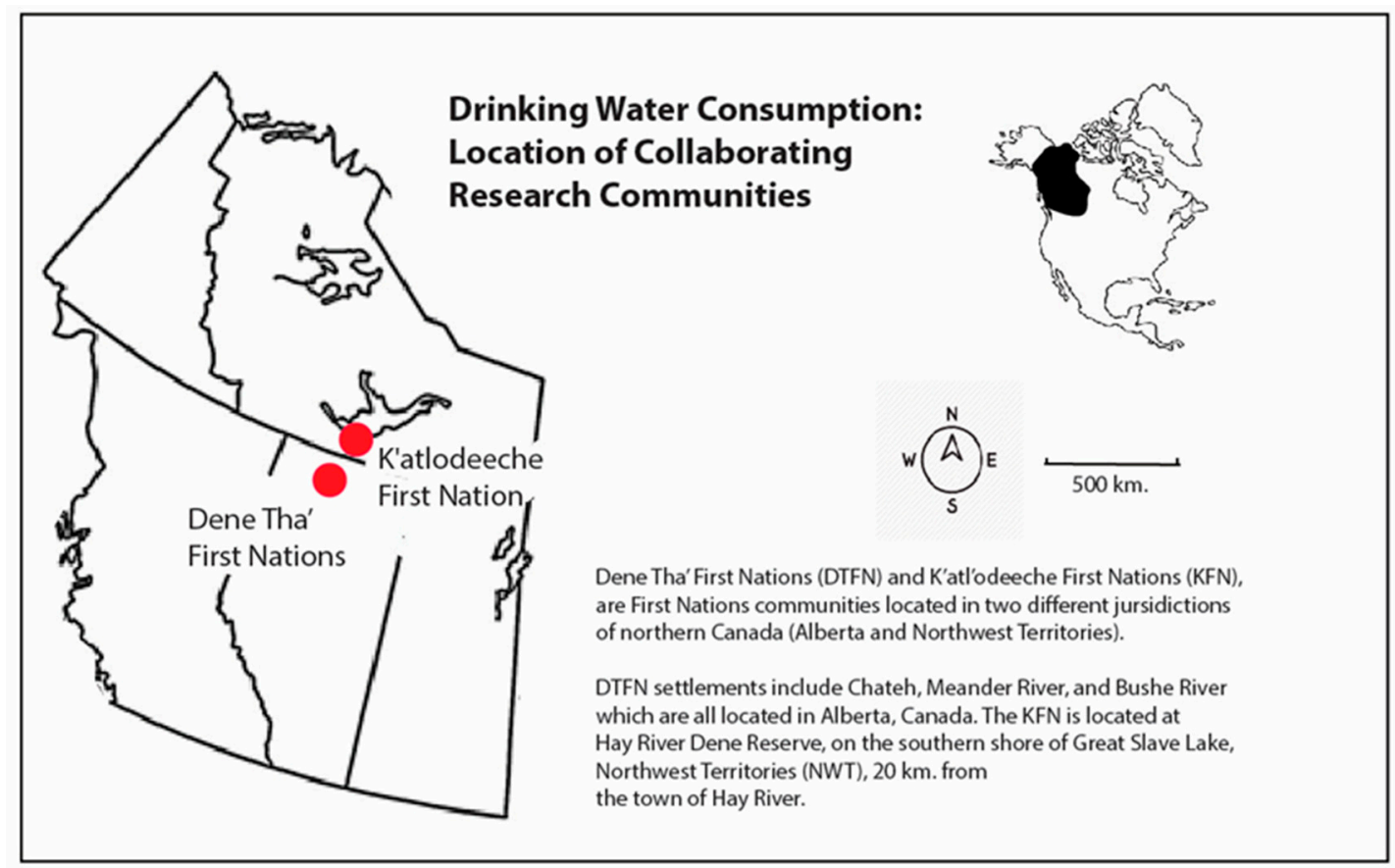

Figure 1. Map indicating Locations of Collaborating Research Communities.

Kátł'odeeche First Nation is also a Dene community; members signed the Treaty 8 in 1900 and whose reserve lands were created in 1974. The community consists of approximately 300 individuals living on the reserve in about 80 households (http://www.K\T1\textquoterightatl $\backslash \mathrm{T} 1 \backslash$ textquoterightodeeche.com). A school, a variety of businesses, and numerous administrative offices serve the needs of the community. Historically, very little resource extraction took place within the KFN traditional territory; however, this is changing, and members are growing more concerned about potential impacts of various resource extraction industries both within their area and in Alberta as the community is seeing the pollution coming downstream. There have been some problems and concerns associated with resource extraction in the area, including the Giant Mine in Yellowknife, N.W.T. (an abandoned gold mine that has poisoned the area with extensive arsenic contamination) and Pine Point (an abandoned Iron ore mine approximately $91 \mathrm{~km}$ from the KFN. In the KFN, the water is supplied by the city of Hay River, delivered to community households via water truck, and stored in water cisterns either in or under the house. There is a yearly local concern regarding the water at spring breakup and the resulting DWA that impacts the communities' view on the quality and safety of the tap water. Some members have concerns about the consistency and frequency of water cistern testing and cleaning within the households. In this community, individual households are responsible for the cleaning of their own cisterns, and the community Health Representative is responsible for testing the water. The testing of household water is typically only done by request. The approach to data collection and analysis had several dimensions and the data analysis followed a similar approach to Crampton and Ragusa [48].

\subsection{Ethics}

Ethics approval was granted on 22 June 2016 under the project name, "Tracking Change in the Mackenzie River Basin," study ID Pro00065907. Subsequently, a separate ethics application was approved by the University of Alberta Research Ethics Board, project name, "Understanding Changes in Freshwater Ecosystems and Drinking Water in Northern Canada," Study ID Pro00064419, granted on 24 November 2016. The ethics approval for the work conducted in the Northwest Territories came from the Aurora Research Institute, License No. 16045 issued on 9 February 2017 under the project name, "Understanding Changes in Freshwater Ecosystems and Drinking Water in Northern Canada." 


\subsection{Respondents}

Dene Tha' First Nations is currently comprised of three settlements (Bushe River, Chateh, Meander River). A total of 49 interviews were conducted in 2016. In Bushe River-14 out of 146 households were interviewed or 9.59 percent. In Chateh-24 out of 280 households were interviewed or 8.57 percent. In Meander River-11 out of 122 households interviewed or 9.02 percent. There were 27 females that ranged from 20 to 84 years of age, with an average of 56 years of age. The education levels for women ranged from no education to university degrees, with an average of grade 10. Twenty-two males ranged from 22 to 86 years of age, with an average of 53.7 years of age. The education levels ranged from no education to some university education, with an average of grade 8.5. Kát1'odeeche First Nations consists of one community. A total of 50 interviews were conducted with members from 46 KFN households. Given there are 80 households in this community, this was a highly representative sample. (57.5\%). This number included 48 interviews on the Hay River Reserve and an additional 2 interviews of KFN members from Hay River, NWT. Eighteen males were interviewed ranging from 24 to 78 years of age, with an average of 49.56 years. These male respondents had education levels from grade 6 to university degrees, with an average of grade 10 education. Thirty-two females were interviewed, that ranged from 21 to 83 years of age, with an average of 51.16 years. The female interviewees had education levels ranging from grade 3 to university degrees with an average of grade 10.36.

\subsection{Methods}

All analyses were conducted using the entire sample. Findings in the results section are presented as descriptive statistics to illustrate patterns in drinking water use in the home and on the land. Additional results from simple bivariate analysis are offered to explain other patterns in the data. Quantitative data were analyzed using PSPP with Pearson's correlations; $t$-tests were also performed to test for significant relationships between various independent and dependent variables. The non-normative distribution of results precluded regression analysis. The main dependent variable considered was bottled water consumption (Table 1). Other dependent variables related to drinking water risk perception are presented in Table 2; Tables 4-6. These variables were developed based on responses to the questions: "Do you drink water from the land?" "Why or Why not?" as well as "Do you drink water from the home?" "Why or Why not?". The independent variables considered in the analysis were age (born before or after 1964), gender, employment status, and education (Tables 7-9).

The data collection instrument included both qualitative (short answer) and survey style questions. While a more standardized and structured survey would have made data collection and analysis simpler, a more conversational approach to interviews was needed to ensure the comfort of interviewees. Since answers to many questions were provided in the interviewee's "own words" (i.e., not standardized for all interviewees), qualitative thematic analysis had to be conducted to utilize the data in quantitative analysis. However, in many instances the responses were not lengthy enough to present as narrative. Responses were coded according to themes and then grouped according major themes (i.e., "the water is no good" and the "water is not healthy" were similarly grouped under the theme, "the water is not healthy"). All interviewee responses were read and independently coded by the first and second authors. Initial codes were compared and refined collaboratively by the researchers until inter-coder reliability was achieved whereby the authors agreed upon the suitability of each code for each response and the relevance of the major themes (i.e., code groupings).

Analysis to determine the relationships between variables was carried out with the intention of learning more about the factors that influenced drinking consumption patterns. We were particularly interested in the variables that were evidenced to the semi-structured research questions: "Do you drink water from the home? Why/Why not? Do you drink water from the land? Why/Why not?" Other variables evidenced as important from the literature (e.g., age, education, gender) were also used to explain variation in the data. 


\section{Results}

Data from 99 interviews about bottled water consumption is presented in this section in relation to the two main sets of questions asked during the interview process. The sources of water which are normally consumed by the respondents both within the home and from the land are presented in Table 1. In the DTFN, most people drank bottled water in both the home and while on the land. In the KFN, although lower than the DTFN, roughly a third of the respondents drank bottled water while in the home. On the land, more similar results are seen in relation to the DTFN when examining bottled water consumption in that most respondents regularly drink bottled water. It should be noted that 2 females did not go on the land in the KFN; therefore, they were not included in the calculations for these statistics.

Table 1. Water Sources Normally Consumed.

\begin{tabular}{|c|c|c|c|c|c|}
\hline & \multicolumn{2}{|c|}{ Male Respondents } & \multicolumn{2}{|c|}{ Female Respondents } & \multirow{2}{*}{$t$ Test } \\
\hline & Number & $\%$ & Number & $\%$ & \\
\hline \multicolumn{6}{|l|}{ Normally Drinks at Home: } \\
\hline \multicolumn{6}{|l|}{ Dene Tha' First Nations } \\
\hline Bottled water & 12 & 54.6 & 20 & 74.1 & $1.66 *$ \\
\hline Tap water & 6 & 27.3 & 7 & 25.9 & -0.27 \\
\hline Both Tap/Bottled water & 3 & 13.6 & 0 & 0.0 & $-2.12 *$ \\
\hline Other & 1 & 4.5 & 0 & 0.0 & $-1.16^{*}$ \\
\hline Total Respondents & 22 & 100 & 27 & 100 & \\
\hline \multicolumn{6}{|l|}{ Kátt'odeecheFirst Nations } \\
\hline Bottled water & 7 & 38.9 & 10 & 31.3 & -0.14 \\
\hline Tap water & 6 & 33.3 & 17 & 53.1 & 0.68 \\
\hline Both Tap/Bottled water & 4 & 22.2 & 5 & 15.6 & -0.72 \\
\hline Total Respondents & 18 & 100 & 32 & 100 & \\
\hline \multicolumn{6}{|l|}{ Normally Drinks on Land: } \\
\hline \multicolumn{6}{|l|}{ Dene Tha' First Nations } \\
\hline Bottled & 18 & 81.8 & 22 & 81.5 & 0.10 \\
\hline Bottled/Natural Source Water & 2 & 9.1 & 2 & 7.4 & -0.30 \\
\hline Bring Tap Water & 0 & 0.0 & 2 & 7.4 & 1.24 * \\
\hline Water from the Land & 2 & 9.1 & 1 & 3.7 & -0.86 \\
\hline Total respondents & 22 & 100 & 27 & 100 & \\
\hline \multicolumn{6}{|l|}{ Kátt'odeecheFirst Nations } \\
\hline Bottled & 9 & 50.0 & 25 & 83.3 & 1.49 * \\
\hline Bottled/Natural Source Water & 2 & 11.1 & 0 & 0.0 & -0.69 \\
\hline Water from the Land & 7 & 38.9 & 5 & 16.7 & $-2.09 *$ \\
\hline Total respondents & 18 & 100 & 30 & 100 & \\
\hline
\end{tabular}

* Significant at $p<0.05$.

\subsection{Worries about Health and Safety}

When examining the reasoning behind individual preferences of water sources for consumption (see Table 2), safety/health concerns were shown to play a crucial part in the decisions of respondents for their choices of safe drinking water, especially in the DTFN. For these calculations, the 2 individuals from the KFN who did not go on the land were not included. 
Table 2. Reasons for Choices Not to Drink Water from the Home/Land.

\begin{tabular}{|c|c|c|c|c|}
\hline & \multicolumn{2}{|c|}{ Male Respondents } & \multicolumn{2}{|c|}{ Female Respondents } \\
\hline & Number & $\%$ & Number & $\%$ \\
\hline \multicolumn{5}{|c|}{$\begin{array}{l}\text { Do you regularly drink bottled water at } \\
\text { home? If yes, why? }\end{array}$} \\
\hline \multicolumn{5}{|c|}{ Dene Tha' First Nations } \\
\hline Taste/Smell & 9 & 40.9 & 9 & 33.3 \\
\hline Health/Safety & 10 & 45.5 & 14 & 51.9 \\
\hline Ease/Access & 1 & 4.5 & 2 & 7.4 \\
\hline Other & 2 & 9.1 & 1 & 3.7 \\
\hline \multicolumn{5}{|c|}{ Kátt'odeeche First Nations } \\
\hline Taste/Smell & 10 & 55.6 & 14 & 43.8 \\
\hline Health/Safety & 5 & 22.7 & 8 & 25.0 \\
\hline Ease/Access & 3 & 13.6 & 5 & 15.6 \\
\hline Other & 1 & 4.5 & 1 & 3.1 \\
\hline \multicolumn{5}{|c|}{$\begin{array}{l}\text { Do you regularly drink bottled water } \\
\text { when on the land? If yes, why? }\end{array}$} \\
\hline \multicolumn{5}{|c|}{ Dene Tha' First Nations } \\
\hline Taste/Smell & 0 & 0.0 & 2 & 7.4 \\
\hline Health/Safety & 8 & 36.4 & 11 & 40.7 \\
\hline Ease/Access & 11 & 50.0 & 15 & 55.6 \\
\hline Other & 0 & 0.0 & 0 & 0 \\
\hline \multicolumn{5}{|c|}{ Kátt'odeeche First Nations } \\
\hline Taste/Smell & 0 & 0.0 & 1 & 3.3 \\
\hline Health/Safety & 4 & 22.2 & 13 & 43.3 \\
\hline Ease/Access & 7 & 31.8 & 12 & 40.0 \\
\hline Other & 0 & 0.0 & 0 & 0.0 \\
\hline
\end{tabular}

Respondents could give multiple reasons for consumption.

It became apparent early in the interview process that there were sources that were considered by many respondents to be important natural water supplies. To analyze the degree of importance of these sources to the two communities, after the first few interviews, more questions were added about the perceived degree of safety regarding five natural water sources: Muskeg filtered water, spring water, rainwater, snow water, and ice water (see Table 3). Because not everyone was asked about these specific sources during the first few interviews, the numbers used in calculating these percentages indicated in Table 3 was done using only the responses from people who were specially asked about, or in the case of the first few interviews, voiced an opinion of the quality of these natural sources of water. In the DTFN, all five sources were considered safe and important sources of water by a majority of the respondents. In particular, water filtered by muskeg was a particularly important and safe source of water for the male residents. In the KFN, muskeg water is much less significant as a source of drinking and the corresponding levels of trust were lower as well. Sources of spring water is not readily available in the immediate area and the related perceived levels of safety were also lower than average. Most water consumed on the land came from the Great Slave Lake in either liquid or frozen form. 
Table 3. Safe Community Natural Sources of Water.

\begin{tabular}{cccccc}
\hline & \multicolumn{2}{c}{ Male Respondents } & \multicolumn{2}{c}{ Female Respondents } & \multirow{2}{*}{ t-Test } \\
\cline { 2 - 5 } & Number & $\mathbf{\%}$ & Number & $\mathbf{\%}$ & \\
\hline DTFN & & & & & \\
Muskeg Water & 18 & 90.0 & 13 & 48.2 & $-3.12 *$ \\
Spring Water & 16 & 84.2 & 19 & 70.4 & $-0.98 *$ \\
Rainwater & 10 & 58.8 & 11 & 47.8 & -1.02 \\
Snow Water & 16 & 80.0 & 15 & 55.6 & -0.91 \\
Ice Water & 14 & 82.4 & 13 & 56.5 & $-1.70 *$ \\
\hline KFN & & & & & \\
Muskeg Water & 6 & 33.3 & 12 & 37.5 & 0.69 \\
Spring Water & 6 & 33.3 & 3 & 9.4 & -1.03 * \\
Rainwater & 11 & 61.1 & 19 & 59.4 & -0.08 \\
Snow Water & 16 & 88.9 & 23 & 71.9 & -0.81 \\
Ice Water & 18 & 100 & 27 & 84.4 & -1.71 * \\
\hline
\end{tabular}

In the DTFN, additional natural water sources beyond the five already mentioned that were considered good or safe were running water sources (20 people), standing water sources (7 people) and specific water sources ( 7 people). In the KFN, the Great Slave Lake (48 people), most natural sources (15 people), running water sources (4 people) and specific water sources ( 3 people) were mentioned as good or safe additional water sources.

One of the interview questions was why certain natural water sources were considered safe (see Table 4). In the DTFN, the top three answers given were that muskeg water was naturally filtered, that the grotto spring was holy and built by Reverend Merriman, and that moving water is better. In the KFN, the three top reasons given why specific natural water sources were good were that it was clean, that it tasted good, and that it was easy access.

Table 4. Why are Natural Sources of Water Good?

\begin{tabular}{ccc}
\hline & DTFN & KFN \\
\hline Muskeg Naturally Filtered & 9 & 2 \\
Grotto is holy and/or built by Priest & 8 & 1 \\
Moving water is better & 5 & 0 \\
Clean & 5 & 25 \\
Others drink it & 4 & 0 \\
Taste & 4 & 7 \\
Free & 1 & 0 \\
Epiritual Connection to Muskeg & 1 & 0 \\
Easy & 0 & 2 \\
Haven't heard anything bad about it & 0 & 1 \\
Rain is from Heaven & 0 & 1 \\
\hline Respondents could give multiple answers or no answer.
\end{tabular}

During the interview, the participants were asked what natural sources of natural water are not considered safe to drink (see Table 5). In the DTFN, the top three answers for poor natural water sources were everywhere, lakes in general, and specifically Zama Lake. In the KFN, the majority mentioned the Hay River, which travels north up through the DTFN territory in the KFN territory. The two other top answers for poor natural water sources were most natural sources and ponds. 
Table 5. What Natural Sources are Poor?

\begin{tabular}{ccc}
\hline & DTFN & KFN \\
\hline Everywhere & 16 & 0 \\
Lakes & 9 & 0 \\
Most Natural Sources & 0 & 4 \\
Zama Lake & 8 & 0 \\
Standing water & 5 & 2 \\
Rivers & 5 & 2 \\
Creeks & 0 & 2 \\
Anywhere near Oil and Gas & 4 & 0 \\
Ponds & 0 & 3 \\
Hay River & 3 & 30 \\
Rainbow Lake & 2 & 0 \\
Sousa Creek & 2 & 0 \\
Chateh & 2 & 0 \\
Anywhere near towns & 2 & 0 \\
Habay & 1 & 0 \\
Natural Precipitation & 1 & 0 \\
Bushe River & 1 & 0 \\
Sandy Creek & 2 & 3 \\
Down South & 0 & 1 \\
Polar Lake & 0 & 1 \\
Great Slave Lakes around edges & 0 & 1 \\
\hline
\end{tabular}

Respondents could give multiple answers or no answer.

When asked why the natural water sources were considered unsafe (see Table 6), the health concerns related to resource extraction in both areas were expressed as major points of concerns for natural sources of water. In the DTFN, oil and gas extraction activity was the biggest concern as to why people considered the natural water sources to be unsafe. Additionally, pollution, the dirtiness of the water, and the local sawmill were the most commonly given answers. In the KFN, the biggest concern over natural sources of water was pollution with additional concerns over the dirtiness of the water and oil and gas were the most common answers given. Respondents were able to offer more than one answer to this question.

Table 6. Why are Natural Sources Bad?

\begin{tabular}{ccc}
\hline & DTFN & KFN \\
\hline Oil and gas & 29 & 7 \\
Pollution & 10 & 23 \\
Dirty & 5 & 16 \\
Sawmill & 5 & 0 \\
Fish factors & 3 & 0 \\
Taste & 3 & 1 \\
Told not safe & 3 & 0 \\
Garbage & 2 & 4 \\
Low water level & 1 & 0 \\
Smells bad & 1 & 1 \\
Stale & 1 & 0 \\
Murky & 0 & 5 \\
Beaver fever & 0 & 4 \\
Dump in Hay River & 0 & 4 \\
Arsenic in Yellowknife & 0 & 3 \\
Sewage & 0 & 2 \\
\hline
\end{tabular}


Table 6. Cont.

\begin{tabular}{ccc}
\hline & DTFN & KFN \\
\hline Pig farm on Hay River & 0 & 1 \\
Smell & 0 & 1 \\
Bugs & 0 & 1 \\
Algae & 0 & 1 \\
Pine Point mine & 0 & 1 \\
\hline
\end{tabular}

Respondents could give multiple answers or no answer.

\subsection{Water Advisories}

In the DTFN, 15 of the 49 households interviewed (30.6 percent) recalled having previously received boil water advisories for their tap water. In the KFN, only 2 of the 46 households interviewed remembered receiving individual water advisories; however, every year during spring break-up, the entire community is placed on a boil water advisory due to concerns of contamination of the tap water. In all cases of individual water advisories in both communities, only one household stated that they received a follow-up notice that their water was safe to drink.

\subsection{Level of Available Information}

Many of the interviewees in both communities did not know when their cisterns were last cleaned or tested. In the DTFN, 12 of 37 interviewees who had cisterns did not know when their cistern was last cleaned, and 16 of 37 interviewees did not know when their cistern was last tested. Nine of the 12 people who did not know when their cisterns were last cleaned regularly drank bottled water. Twelve of the 16 interviewees who did not know when their cistern was last tested drank only bottled water. In the KFN, 11 of 49 interviewees did not know when their cistern was last cleaned, and 10 of 49 interviewees did not know when it was last tested. For those who did not know when the cistern was last cleaned, 3 of 11 regularly drank bottled water. Of those who did not know when their cistern was last tested, 4 of 10 regularly drank bottled water.

\subsection{Organoleptics}

As shown in Table 2, taste played a significant role in people's consumption patterns in the home in both communities. However, taste plays a much less significant role in water consumption patterns while on the land.

\subsection{Demographics and Socio-Economic Variations}

For the purpose of this research, various socio-demographics were analyzed (see Tables 1-3 and Tables 7-9) that were previously studied by other academics to see if this study confirms or contradicts those research findings.

\subsection{Gender}

Gender is presented in various tables to better understand the relationship between gender and consumption patterns (see Tables 1-3). In the DTFN, statistically significant relationships between gender and consumption patterns were shown in three of the four categories examined. Overall, female respondents (74.1 percent) were much more likely to regularly consume bottled water at home than the male respondents (54.6 percent). While on the land, the statistical difference was minimized since both a very large percentage of both men (81.8 percent) and women ( 81.5 percent) drink bottled water regularly. In the KFN, no significant relationships were indicated in the results for consumption patterns in the home. Overall, the home results indicate that fewer women (31.3 percent) drink bottled water than men (38.9 percent). While on the land, two statistically significant relationships between gender and consumption choices are shown. On the land, more women (83.3 percent) regularly drink 
bottled water than men (50.0 percent) and men are statistically more likely to consume natural sources of water.

In Table 3, the various types of natural sources of water commonly used for drinking are examined. In the DTFN, for three of the five sources (muskeg, spring water and ice water) a significant relationship between gender and what sources are considered safe exists. In the DTFN, 90 percent of males considered muskeg water safe, versus 48.2 percent of females. Spring water was considered safe by 84.2 percent of males and 70.4 percent of female respondents. Ice water was considered safe by 82.4 percent of males while only 56.5 percent of females thought it was safe. However, in all cases, female respondents were more likely to consider the natural sources of water unsafe to drink than male respondents. In the KFN, significant relationships between gender and consumption choices existed for ice water (100 percent male and 84.4 percent females) and spring water (33.3 percent male and 9.4 percent female). Muskeg was the only natural water source considered safer by more females (37.5 percent) versus males (33.3 percent). The other two sources indicated similar relationships between male and female respondents in consumption patterns in relation to natural sources of water.

\subsection{Age}

For ease of analysis in the age category, the data were broken down into 2 groups-members that were born after and including 1965, and member that were born before 1965. This date was chosen because it split the number of respondents roughly in half and was approximately the average age of the respondents. The results are presented in Table 7. In the DTFN, 70 percent of those respondents who were born prior to 1965 primarily drank bottled water within the home versus 60 percent of those respondents who were born in 1965 or later. The only significant relationship indicated in this category of home water sources was in the KFN where 54.2 percent of respondents born prior to 1965 primarily drank bottled water versus 15.4 percent of those who were born in 1965 or later.

The opposite effect is noted when examining the natural water source consumption habits. In the DTFN, almost 4 out of 5 people (79.3 percent) that were born before 1965 drank bottled water while on the land, compared to 85 percent of people what were born after and including 1965. In the KFN, this same drinking pattern was also shown in that 69.6 percent of people born before 1965 drank bottled water on the land while 72 percent of people born after and including 1965 drank bottled water.

Table 7. Bottled Water Consumption by Age.

\begin{tabular}{|c|c|c|c|c|c|}
\hline & \multicolumn{2}{|c|}{ Born 1964 or Prior } & \multicolumn{2}{|c|}{ Born 1965 or After } & \multirow{2}{*}{$t$-Test } \\
\hline & Number & $\%$ & Number & $\%$ & \\
\hline \multicolumn{6}{|l|}{ Dene Tha' First Nations } \\
\hline In home & $20 / 29$ & 70.0 & $12 / 20$ & 60.0 & -0.64 \\
\hline While on the Land & $23 / 29$ & 79.3 & $17 / 20$ & 85.0 & 0.50 \\
\hline \multicolumn{6}{|c|}{ K'atl'odeeche First Nations } \\
\hline In home & $13 / 24$ & 54.2 & $4 / 26$ & 15.4 & $-3.11 *$ \\
\hline While on the Land & $17 / 23$ & 73.9 & $18 / 25$ & 72.0 & -0.45 \\
\hline
\end{tabular}

\subsection{Education}

The relationship between education levels and consumption patterns is presented in Table 8 . In the DTFN, education levels appeared to have a significant relationship with consumption patterns while on the land. However, education levels did not appear to be related to consumption choices while in the home. In the KFN, the similar relationship between education and consumption choices while on the land is indicated in that higher educated people drink more bottled water. Education levels do not appear to have a significant relationship on consumption choices while in the home; however, educated people generally appear to be less likely to drink bottled water. 
Table 8. Bottled Water Consumption by Education Levels.

\begin{tabular}{cccccc}
\hline & \multicolumn{2}{c}{ Grade 9 or Less } & \multicolumn{2}{c}{ Grade 10 or More } & \multirow{2}{*}{ t-Test } \\
\cline { 2 - 4 } & Number & $\%$ & Number & $\%$ & \\
\hline $\begin{array}{c}\text { Dene Tha' First Nations } \\
\text { In home }\end{array}$ & $15 / 23$ & 65.2 & $17 / 26$ & 65.4 & 0.01 \\
$\quad$ While on the Land & $16 / 23$ & 69.6 & $24 / 26$ & 92.3 & $2.10 *$ \\
\hline $\begin{array}{c}\text { K'atl'odeeche First Nations } \\
\text { In home }\end{array}$ & $5 / 12$ & 38.5 & $12 / 37$ & 32.4 & -0.39 \\
$\quad$ While on the Land & $7 / 12$ & 58.3 & $27 / 36$ & 75 & 0.36 \\
\hline \multicolumn{5}{c}{$*$ Significant at $p<0.05}$.
\end{tabular}

\subsection{Income}

Table 9 presents the analysis of the relationship between employment status and consumption patterns. In the DTFN, there was a significant relationship shown between employment status and drinking bottled water. Interestingly, a higher percentage of people with no or limited income indicated a higher rate of bottled water consumption. However, the results indicate that employed people are more likely to drink bottled water then people with limited income while on the land. In the KFN, a significant relationship was indicated between employed people and drinking bottled water where people with higher levels of income were more likely to drink bottled water in the home. While on the land, opposite results were shown in the relationship between unemployed respondents and their corresponding consumption patterns in that they were more likely to drink bottled water than employed people.

Table 9. Bottled Water Consumption by Employment Status.

\begin{tabular}{|c|c|c|c|c|c|}
\hline & \multicolumn{2}{|c|}{ Employed } & \multicolumn{2}{|c|}{ Not Emp./Retired } & \multirow{2}{*}{$t$-Test } \\
\hline & Number & $\%$ & Number & $\%$ & \\
\hline \multicolumn{6}{|l|}{ Dene Tha' First Nations } \\
\hline In home & $14 / 26$ & 53.9 & $18 / 23$ & 78.3 & 1.82 * \\
\hline While on the Land & $22 / 26$ & 84.6 & $18 / 23$ & 78.3 & -0.56 \\
\hline \multicolumn{6}{|l|}{ K'atl'odeeche First Nations } \\
\hline In home & $12 / 29$ & 41.4 & $5 / 21$ & 23.8 & -1.93 * \\
\hline While on the Land & $17 / 27$ & 63.0 & $17 / 21$ & 81 & 0.08 \\
\hline
\end{tabular}

\section{Discussion}

\subsection{The Role of Knowledge in Risk Perception}

These findings support previous research that show increased levels of safety concerns over water sources results in an increase of bottled water consumption [1,4,42,43]. A significant number of interviewed community members in the DTFN regularly consume bottled water due to concerns over the safety of household and natural source water sources. The lower levels of safety concerns over water in the KFN are related to a lower level of consumption of bottled water than the DTFN; however, bottled water consumption within the KFN community is still higher than the national average. The use of spring water, rainwater, snow water, ice water and muskeg water as viable sources in the DTFN shows the importance of natural sources of water while on the land hunting and fishing. It can be difficult for community members to bring drinking water with them while on the land, so they must use water sources available to them in the area. This does not necessarily mean that these natural sources of water are safe but are thought to be the safest options available in the area. For members of 
the KFN, the Great Slave Lake was the largest source of natural water, with almost all interviewees considering it a safe source of drinking water.

In the DTFN, safety concerns were expressed over the water cisterns including the frequency of cleaning and testing and but also what had been found in the cisterns. The cisterns in the DTFN are located outside and consist of concrete pieces that may have originally fit well together, but decades of ground upheaval have caused many of them to no longer maintain structural integrity, which allows dirt and other items to get into the tanks. Many people complained about hearing of, or having found, rodents and insects and garbage in water cisterns. There have also been reports of diapers and garbage being found in the cisterns. Having contaminated water cisterns would mostly likely increase the levels of safety concerns over the water that is contained within.

Some interesting parts of the interviews were the interaction between personal beliefs and the perceived level of safety concerns people had. Some interviewees mentioned that they felt muskeg water was safer and an important source of water because traditional medicine came from it. There were also people who mentioned that the spring grotto in Meander River was safe because it was built by a man of the church and the water was holy.

The high level of concerns over the safety of natural sources of water in the DTFN is directly related to worries over contamination and pollution by natural resource extraction activities in the area. Oil and Gas development, past and present, is extensive throughout the traditional DTFN territory and is very problematic for the quality of natural water sources due to contamination. These safety concerns result in the consumption of bottled water when it was feasible while on the land. If taking bottled water out on the land was not possible, drinking water from the previously mentioned sources is the common practice to help minimize the problem.

In the KFN traditional territory, resource extraction activities have been limited, which has resulted in fewer safety concerns over natural sources of water and a corresponding lower consumption of bottled water while on the land. There were still concerns over pollution, especially from what was coming downstream from Alberta and resource extraction activities that are on the increase in the area. Therefore, it is hypothesized that, in the future, higher levels of pollutants and impacts from increased resource extraction activities in the KFN territory will result in higher consumption of bottled water by community members.

\subsection{Water Advisories}

Both the KFN and the DTFN have had various drinking water advisories issued over the last few years. It was mentioned by a few people in the DTFN that even though they may not have received a water advisory, they knew family members or friends that have received them. It is hypothesized that despite their own households not being impacted, knowing other people had received DWAs may lead to higher levels of risk perception over health concerns over the water sources. In the KFN, very few households mentioned receiving individual DWAs; however, the community itself is placed on an annual DWA during the spring break-up of the Hay River and the GSL. The high number of DWAS in the DTFN and the annual DWA in the KFN help to explain the heightened levels of risk perception in the communities and the resulting increased bottled water consumption. These results are like the results from previous research that showed a relationship between bottled water consumption and the existence of advisories $[23,33,41]$.

\subsection{Level of Available Information}

The results in this category appear to have somewhat conflicting results. The results from the DTFN appear to support previous research that claims a lack of knowledge about water quality results in an increase in the consumption of bottled water [40]. In the DTFN, 75 percent of people who did not know when their cisterns were last cleaned or tested regularly drank bottled water. This is higher than the overall average of 65 percent of respondents who drank bottled in the community. However, in the KFN, 27 percent of those who did not know when their cistern was last cleaned regularly drank 
bottled water versus the 34 percent overall. For those individuals in the KFN who did not know when their cistern was last tested, 40 percent regularly drank bottled water versus the 34 percent overall of all respondents. Perhaps the smaller number of interviewees who did not know when their cisterns were cleaned last can explain the inconsistency with the other results. In any case, most of the results appear to support previous research that a lack of knowledge about the quality of water will typically result in a higher rate of consumption of bottled water.

\subsection{The Role of Taste and Smell in Risk Perception}

This research appears to confirm prior research that the physical qualities of the water play a crucial part in decisions regarding water consumption practices $[15,20,30,41]$. As shown, taste played a very important role in an individual's consumption of bottled water at home, both in the DTFN and the KFN. While on the land, where safety and convenience were a bigger reason for bottled water consumption, taste plays a drastically lesser role in decisions about drinking water.

\subsection{Gender}

The examination of gender shows that the results found in this research are mostly consistent with findings from previous research; specifically it appears to be a relationship between gender and consumption habits of individuals in these two communities, The results from the DTFN appear to confirm previous results, while the KFN results somewhat contradict previous results when examining this variable $[1,4,33]$. In the DTFN, more women regularly drink bottled water at home than men. While on the land, the gender gap is eliminated, with many of both genders regularly drinking bottled water, perhaps because of the severity of the situation for natural source water within the area. In the KFN, the relationship of gender and bottled water consumption is inconsistent with other findings in that within the home, fewer women drink bottled water than men. This could perhaps be explained by the low number of participants who stated they drank bottled water in the home. However, while on the land, far more women stated they regularly drank bottled water than men. This would suggest that women perceive bottled water as safer than natural water sources while on the land.

An examination of what specific natural sources of water are considered safe further details gender differences and indicates that women are much less likely to think that natural sources of water are safe for consumption. For the specific natural sources of water including muskeg water, snow water, ice water, rainwater, and spring water, only muskeg water was considered safer by women (37.5 percent) in the KFN than men ( 33.3 percent). In all other circumstances, men were typically much more confident in the safety of these natural sources than women. These results support previous research that shows that women have much lower confidence in natural sources of water than men.

\subsection{Age}

Age does not appear to have a fully consistent relationship with consumption habits with the people interviewed, which may help to explain the conflicting results of previous studies $[1,33]$. Splitting the interviewees into two groups (those born before and those born after 1965) shows that in the two communities, there appears to be consistency in the results when examining specific types of drinking water. Both communities show that younger people are less likely to drink bottled water while in the home, while older people are less likely to drink bottled water while on the land.

Additional research could help further develop this variable as, on the surface, the results appear to be contradictory. Why are the same individuals changing their consumption patterns depending on where they are? Perhaps familiarity or repetition of habits would help explain. If young people have grown up with access to running tap water and are accustomed to the taste of chlorine (which is a complaint of some respondents), they may be more likely to drink tap water. Older people on reserves often did not have access to running water in their homes when growing up and were more accustomed to using alternate sources of drinking water and not often exposed to the taste of chlorine. 
While on the land, older people grew up drinking local water sources while younger people have not due to the increased concerns over pollution or degradation of natural water sources.

\subsection{Education}

The results from this research, although contradictory in some ways to previous surveys that indicate that more educated people are less likely to drink bottled water, makes sense when you look at the conditions that exist within the communities, especially within the DTFN. Research in the past showed that less educated individuals are more likely to drink bottled water [1]. However, the drinking water situation in many Indigenous communities, especially within the DTFN, is so problematic that those with a higher education are more likely to drink bottled water than less educated people because of very legitimate concerns over the safety of the water sources. These results support previous research that shows that individuals with a higher level of education are more concerned about the drinking water in First Nation communities where conditions for water quality are low [33]. These results also support our hypothesis that individuals with higher levels of education are more likely to drink bottled water due high occurrence of problems with drinking water sources in the communities. It should be stated that less educated individuals may still (and probably do) fully understand the concerns of the water sources and the results shows that they are still far more likely to drink bottled water than residents of non-First Nation communities.

In the KFN, although more people drink bottled water in the household than the national average, the results are more typical of those seen in non-indigenous communities. Supplied water in the homes in the KFN, although some problems do exist, is generally considered by most participants (86 percent) to be safe, which explains the lower consumption of bottled water overall and lower bottled water consumption by more educated people. As these results indicate, people with more education are less likely to drink bottled water in the home and this supports the findings of Dupont et al. [1]. Similar results are shown for on-the-land water consumption habits. Although bottled consumption while on the land is very high for both categories, it appears that more highly educated people are still less likely to consume bottled water while on the land.

\subsection{Income}

The relationship between income and water consumption patterns seem to be in contradiction between communities and when compared with findings from other research. These results may indicate how high the level of perceived problems is with drinking water both in the home and while on the land, especially within the DTFN. Although level of income was not asked (stopped after the first few interviews) due to the sensitive nature and respondent reaction to the question, employment status was examined. If people indicated employment, it was assumed that they had income of some form. It appears that regardless of employment status, the extreme conditions associated with the DTFN household water meant that bottle water consumption was very high, which supports the findings of McSpirit and Reid [45] that examined concerns about pollution in the Appalachian Mountains and the resulting impacts on water consumption habits. In fact, of the individuals interviewed in the DTFN, those who were unemployed were more likely to consume bottled water in the home than those who were employed. This appears to contradict the expected outcome in that people with lower levels of income would normally spend less money on bottled water. It could be related to more interviewed employed people were on pressurized delivery lines verses cisterns, which may lower the possibility of concerns over the tap water and result in lower rates of bottled water consumption; however, further research would be needed to clarify why this trend occurs in the DTFN. The opposite consumption patterns occur in the KFN, where household water conditions are better. These results support the findings of Dupont et al. (2010) that show that availability of money is related to a higher rate of bottled water consumption. However, while on land, the opposite relationship is indicated. To better understand this unexpected outcome, further research will be needed to be conducted. Overall, in both 
communities, the vast majority of people regularly drank bottled water while on the land, regardless of income levels, which would be reflective of concerns over safety as observed by McSpirit and Reid [43].

\section{Conclusions}

Many Indigenous communities across Canada lack access to clean drinking water, a circumstance symbolic of the legacy of colonization and socio-economic marginalization experienced in almost every part of the country. Many individuals and households on who cannot access potable water in their homes or on the land, are faced with the burden of buying bottled water. This growing trend has implications for local economies as well as matter in a broader context of ecological sustainability. Much of this decision is driven by risk perception, or the beliefs and judgments held about potential harms of their water sources. Risk perception can be influenced by many factors internal to a community (i.e., cultural beliefs) as well as external factors such as environment or jurisdiction. Through case study research with Kátt'odeeche First Nations and Dene Tha' First Nations, this study attempted to unpack how risk perceptions differs in these two communities which are located in the unique jurisdictions of Alberta and the Northwest Territories and how that may affect bottled water consumption. Bottled water consumption reported through this study is higher than the reported national average; although drivers of such consumption may in part be convenience, perceptions that the water is not safe to drink seems to be a major factor behind this pattern. This is particularly true in Dene Tha' First Nation where they expressed greater concern about the poor quality of drinking water in their community and on the land when compared to interviewees of K'atl'odeeche First Nation.

Concerns about the potability of drinking water expressed in this research are consistent with previous research with First Nations, Métis and Inuit communities in Canada [4,10,23]. The work is important in demonstrating how broader drivers of change (e.g., resource development in the case of Dene Tha' First Nations in Northern Alberta) have affected the quality of, and access to, water sources on the land (e.g., muskeg water) of traditional importance to the Dene and Cree people. We have also aspired to provide insight as to how jurisdiction and the associated services of governments are critical to addressing concerns about water from the land and ensuring access to clean water in the home. Based on the outcomes of this study, those living in the Northwest Territories are much better off than those in Northern Alberta where poor water quality on the land and in the home has led to higher than average consumption of bottled water when compared to the Canadian average [4]; but whereas drivers of bottled water consumption may be lifestyle oriented in many populations, it is clear from this study that the First Nations families in Northern Alberta are purchasing bottled water as a result of health concerns about poor infrastructure and contaminated source water supplies. As such comparisons between study outcomes and data on bottled water consumption in other parts of Canada and among other populations must be considered carefully.

Although the research was carried out with two First Nations in Northern Alberta and the Northwest Territories, the outcomes may be generalizable to other regions of Canada and elsewhere; specifically, our work demonstrates how ensuring access to clean drinking water is not simply a technical issues but requires consideration of the socio-cultural, economic and political factors that shape water quality as well as individual risk perception.

Further research is needed to understand the patterns of drinking water consumption and variations in risk perception with an eye to generating culturally appropriate and sustainable solutions to the drinking water problems faced by Kátt'odeeche First Nations and Dene Tha' First Nations and other Indigenous peoples. 
Author Contributions: The study was conceptualized by N.S., B.P., and participating community partners and governance organizations. The methodological approach and development of the survey instrument involved all authors and representatives of participating communities. Data collection and verification of data with participating individuals and partners was led by N.S., M.C. and D.L. Data analysis was led by N.S. and B.P. and guided by collaborating scholars (John Parkins and Vic Adamowicz). The manuscript was prepared by N.S. and B.P. with input from all authors. All authors have read and agreed to the published version of the manuscript.

Funding: This research was funded by the Social Science and Humanities Research Council of Canada and the Government of the Northwest Territories with a grant to Parlee (SSHRC PG 895-2015-1024 Parlee) and Diane Dupont and Vic Adamowicz: Water Economics Policy and Governance Network (SSHRC grant 895-2011-1029).

Acknowledgments: We acknowledge the support of Dene Tha' First Nations, Kátł'odeeche First Nation, Treaty8 First Nations of Alberta, the Traditional Knowledge Steering Committee of the Mackenzie River Basin Board and the Aboriginal Steering Committee of the Government of the Northwest Territories Water Stewardship Strategy with special thanks to Kevin Ahkimnachie, Peter Redvers, Jennifer Fresque Baxter and Chief James Ahnassay. The author team wishes to particularly thank the participants of the study including the many individuals and families who have supported this work and whose health and well-being has been compromised by poor drinking water quality.

Conflicts of Interest: There are no conflicts of interests reported by any of the authors.

\section{References}

1. Dupont, D.; Adamowicz, W.L.; Krupnick, A. Differences in water consumption choices in Canada: The role of socio-demographics, experiences, and perceptions of health risks. J. Water Health 2010, 8, 671-686. [CrossRef] [PubMed]

2. Ferrier, C. Bottled water: Understanding a social phenomenon. AMBIO A J. Hum. Environ. 2001, 30, 118-119. [CrossRef]

3. Anadu, E.C.; Harding, A.K. Risk perception and bottled water use. J.-Am. Water Works Assoc. 2000, 92, 82-92. [CrossRef]

4. Dupont, D.; Waldner, C.; Bharadwaj, L.; Plummer, R.; Carter, B.; Cave, K.; Zagozewski, R. Drinking water management: Health risk perceptions and choices in First Nations and non-First Nations communities in Canada. Int. J. Environ. Res. Public Health 2014, 11, 5889-5903. [CrossRef] [PubMed]

5. Galway, L.P. Boiling over: A Descriptive Analysis of Drinking Water Advisories in First Nations Communities in Ontario, Canada. Int. J. Environ. Res. Public Health 2016, 13, 505. [CrossRef]

6. Walters, D.; Spence, N.; Kuikman, K.; Singh, B. Multi-barrier protection of drinking water systems in Ontario: A comparison of First Nation and non-First Nation communities. Int. Indig. Policy J. 2012, 3, 8. [CrossRef]

7. Hrudey, S.E. Safe drinking water policy for Canada-turning hindsight into foresight. CD Howe Inst. Comment. 2011, 323. [CrossRef]

8. Morrison, A.; Bradford, L.; Bharadwaj, L. Quantifiable progress of the first nations water management strategy, 2001-2013: Ready for regulation? Can. Water Resour. J./Rev. Can. Des Ressour. Hydr. 2015, 40, 352-372. [CrossRef]

9. Schindler, D.W. The cumulative effects of climate warming and other human stresses on Canadian freshwaters in the new millennium. Can. J. Fish. Aquat. Sci. 2001, 58, 18-29. [CrossRef]

10. Martin, D.; Bélanger, D.; Gosselin, P.; Brazeau, J.; Furgal, C.; Déry, S. Drinking water and potential threats to human health in Nunavik: Adaptation strategies under climate change conditions. Arctic 2007, 60, 195-202. [CrossRef]

11. Bradford, L.E.; Bharadwaj, L.A.; Okpalauwaekwe, U.; Waldner, C.L. Drinking water quality in Indigenous communities in Canada and health outcomes: A scoping review. Int. J. Circumpolar Health 2016, 75, 32336. [CrossRef] [PubMed]

12. Schindler, D.W.; Donahue, W.F. An impending water crisis in Canada's western prairie provinces. Proc. Natl. Acad. Sci. USA 2006, 103, 7210-7216. [CrossRef] [PubMed]

13. Patrick, R.J. Uneven access to safe drinking water for First Nations in Canada: Connecting health and place through source water protection. Health Place 2011, 17, 386-389. [CrossRef] [PubMed]

14. Mora-Rodríguez, J.; Delgado-Galván, X.; Ramos, H.M.; López-Jiménez, P.A. An overview of leaks and intrusion for different pipe materials and failures. Urban Water J. 2014, 11, 1-10. [CrossRef] 
15. Ekos Research Associates. Perceptions of Drinking Water Quality in First Nations Communities and General Population; Ekos Research Associates, 2011; pp. 1-129. Available online: https:/www.ekospolitics.com/ articles/015-11.pdf (accessed on 24 August 2020).

16. Farenhorst, A.; Li, R.; Jahan, M.; Tun, H.M.; Mi, R.; Amarakoon, I.; Kumar, A.; Khafipour, E. Bacteria in drinking water sources of a First Nation reserve in Canada. Sci. Total Environ. 2017, 575, 813-819. [CrossRef]

17. Canter, L.W.; Nelson, D.I.; Everett, J.W. Public perception of water quality risks-influencing factors and enhancement opportunities. J. Environ. Syst. 1992, 22, 163-187. [CrossRef]

18. Eichelberger, L. Household water insecurity and its cultural dimensions: Preliminary results from Newtok, Alaska. Environ. Sci. Pollut. Res. 2018, 25, 32938-32951. [CrossRef]

19. Renn, O.; Rohrmann, B. (Eds.) Cross-Cultural Risk Perception: A Survey of Empirical Studies-Vol. 13; Springer Science \& Business Media: London, UK, 2000.

20. de França Doria, M. Factors influencing public perception of drinking water quality. Water Policy 2010, 12, 1-19. [CrossRef]

21. Bradford, L.E.A.; Vogel, T.; Lindenschmidt, K.-E.; McPhedran, K.; Strickert, G.E.H.; Fonstad, T.A.; Bharadwaj, L.A. Co-design of water services and infrastructure for Indigenous Canada: A scoping review. FACETS 2018, 3, 487-511. [CrossRef]

22. Lebel, P.M.; Reed, M.G. The Capacity of Montreal Lake, Saskatchewan to Provide Safe Drinking Water: Applying a Framework for Analysis. Can. Water Resour. J./Rev. Can. Des Ressour. Hydr. 2010, 35, 317-338. [CrossRef]

23. Castleden, H.; Crooks, V.A.; van Meerveld, I. Examining the public health implications of drinking water-related behaviours and perceptions: A face-to-face exploratory survey of residents in eight coastal communities in British Columbia and Nova Scotia. Can. Geogr./Le Géographe Can. 2015, 59, 111-125. [CrossRef]

24. Bradford, L.; Waldner, C.; McLaughlin, K.; Zagozewski, R.; Bharadwaj, L. A mixed-method examination of risk factors in the truck-to-cistern drinking water system on the Beardy's and Okemasis First Nation Reserve, Saskatchewan. Can. Water Resour. J./Rev. Can. Des Ressour. Hydr. 2018, 43, 383-400. [CrossRef]

25. Hanrahan, M.; Sarkar, A.; Hudson, A. Exploring water insecurity in a northern indigenous community in canada: The "never-ending job" of the southern inuit of black tickle, labrador. Arct. Anthropol. 2014, 51, 9-22. [CrossRef]

26. Morales, S.N. A Glass Half Empty: Drinking Water in First Nations Communities. Aboriginal Policy Res. Volume III Setting Agenda Chang. 2006, 3, 161-185.

27. White, J.P.; Murphy, L.; Spence, N. Water and Indigenous peoples: Canada's paradox. Int. Indig. Policy J. 2012, 3, 1-25. [CrossRef]

28. Maxim, P.S.; White, J.P.; Whitehead, P.C. Toward an index of community capacity: Predicting community potential for successful program transfer. PSC Discuss. Pap. Ser. 2001, 15, 1.

29. Fawcett, S.E.; Jamieson, H.E.; Nordstrom, D.K.; McCleskey, R.B. Arsenic and antimony geochemistry of mine wastes, associated waters and sediments at the Giant Mine, Yellowknife, Northwest Territories, Canada. Appl. Geochem. 2015, 62, 3-17. [CrossRef]

30. Doria, M.F. Bottled water versus tap water: Understanding consumers' preferences. J. Water Health 2006, 4, 271-276. [CrossRef]

31. Health Canada. Ending Long-Term Drinking Water Advisories; Government of Canada: Ottawa, ON, Canada. Available online: https://www.sac-isc.gc.ca/eng/1506514143353/1533317130660 (accessed on 24 August 2020).

32. Burnside, N. National Assessment of First Nations Water and Wastewater Systems: Report Prepared for Indian and Northern Affairs Canada; Neegan Burnside: Orangeville, ON, Canada, 2011.

33. Spence, N.; Walters, D. Is it safe? Risk perception and drinking water in a vulnerable population. Int. Indig. Policy J. 2012, 3, 1-23. [CrossRef]

34. Larson, K.L.; Stotts, R.; Wutich, A.; Brewis, A.; White, D. Cross-cultural perceptions of water risks and solutions across select sites. Soc. Nat. Resour. 2016, 29, 1049-1064. [CrossRef]

35. Sajjadi, S.A.; Alipour, V.; Matlabi, M.; Biglari, H. Consumer perception and preference of drinking water sources. Electron. Physician 2016, 8, 3228. [CrossRef] [PubMed]

36. Skuras, D.; Tyllianakis, E. The perception of water related risks and the state of the water environment in the European Union. Water Res. 2018, 143, 198-208. [CrossRef] [PubMed] 
37. Cote, S.A.; Ross, H.; David, K.; Wolfe, S.E. Walkerton revisited: How our psychological defenses may influence responses to water crises. Ecol. Soc. 2017, 22, 32. [CrossRef]

38. Brown, B.; Wachowiak-Smolíková, R.; Spence, N.D.; Wachowiak, M.P.; Walters, D.F. Why do some first nations communities have safe water and others not? Socioeconomic determinants of drinking water risk. Glob. J. Health Sci. 2016, 8, 99. [CrossRef]

39. Wright, C.J.; Sargeant, J.M.; Edge, V.L.; Ford, J.D.; Farahbakhsh, K.; Shiwak, I.; Flowers, C.; Gordon, A.C.; Harper, S.L.; IHACC Research Team. How are perceptions associated with water consumption in Canadian Inuit? A cross-sectional survey in Rigolet, Labrador. Sci. Total Environ. 2018, 618, 369-378. [CrossRef]

40. Contu, A.; Carlini, M.; Maccioni, A.; Meloni, P.; Schintu, M. Evaluating citizens concern about the quality of their drinking water. Water Sci. Technol. Water Supply 2005, 5, 17-22. [CrossRef]

41. McLeod, L.; Bharadwaj, L.; Waldner, C. Risk factors associated with the choice to drink bottled water and tap water in rural Saskatchewan. Int. J. Environ. Res. Public Health 2014, 11, 1626-1646. [CrossRef]

42. Johnson, B.B. Do Reports on Drinking Water Quality Affect Customers' Concerns? Experiments in Report Content. Risk Anal. 2003, 23, 985-998. [CrossRef]

43. McSpirit, S.; Reid, C. Residents' Perceptions of Tap Water and Decisions to Purchase Bottled Water: A Survey Analysis from the Appalachian, Big Sandy Coal Mining Region of West Virginia. Soc. Nat. Resour. 2011, 24, 511-520. [CrossRef]

44. Horvath, S.; Dickerson, M.O.; MacKinnon, L.; Ross, M.M. The impact of the traditional land use and occupancy study on the DeneTha'First Nation. Can. J. Nativ. Stud. 2002, 22, 361-398.

45. Vanderklippe, N. Toxic waste spill in northern Alberta biggest of recent disasters in North America. Globe Mail Wednesday 2013, 2. Available online: https:/www.theglobeandmail.com/report-on-business/ industry-news/energy-and-resources/apache-pipeline-leaks-60000-barrels-of-salty-water-in-northwestalberta/article12494371/ (accessed on 24 August 2020).

46. Wang, Z.; Fingas, M.; Blenkinsopp, S.; Sergy, G.; Landriault, M.; Sigouin, L.; Lambert, P. Study of the 25-year-old Nipisi oil spill: Persistence of oil residues and comparisons between surface and subsurface sediments. Environ. Sci. Technol. 1998, 32, 2222-2232. [CrossRef]

47. McClure, M. Plains Midstream Charged for Largest Alberta Oil Spill in Decades. Calg. Her. 2013. Available online: www.calgaryherald.com/business/plains+midstream+charged+largest+alberta+spill+ decades/8300811/story.html (accessed on 24 August 2020).

48. Crampton, A.; Ragusa, A.T. Exploring perceptions and behaviors about drinking water in Australia and New Zealand: Is it risky to drink water, when and why? Hydrology 2016, 3, 8. [CrossRef] 